\title{
Implementasi Data Mining Dalam Memprediksi Transaksi Penjualan Menggunakan Algoritma Apriori (Studi Kasus PT.Arma Anugerah Abadi Cabang Sei Rampah)
}

\author{
Paujiah Nur Harahap ${ }^{1}$, Sulindawaty ${ }^{2}$
}

\begin{abstract}
Abstrak-Data mining ialah operasi resourcing dan penggunaan data untuk mencari pola atau hubungan dari sekumpulan data yang berukuran besar. Data mining telah diimpelementasikan pada berbagai aspek, salah satunya pada bidang penjualan produk roti. Pihak perusahaan dapat mengetahui minat pembeli dengan memanfaatkan data mining untuk mengolah data penjualan produk roti. Penelitian ini menganalisis tentang pencarian informasi dari data transaksi penjualan roti menggunakan data mining dengan algoritma apriori. Algoritma apriori merupakan jenis aturan asosiasi (Association Rules) dalam menentukan pola kombinasi itemset dan aturan asosiasi pada PT. Arma Anugerah Abadi Cabang Sei Rampah, yaitu dengan nilai support dan confidence tertinggi adalah Roti Bungkus Coklat Keju dan Roti Bungkus Pres Kelapa dengan nilai support $17 \%$ dan nilai confidence $77 \%$.
\end{abstract}

Kata Kunci-Algoritma apriori; association rules; data mining.

Abstract-Data mining is a operation that involves collecting and using data to find patterns or relationships from large data sets. Data mining has been implemented in various fields, one of which is in the sale of bakery products. The company can find out the buyer's interest by using data mining to process data on sales of bakery products. This study discusses information retrieval from bread sales transaction data using data mining with a priori algorithms. Apriori algorithm is a type of association rule (Association rules) in determining the combination pattern of item set and association rules at PT. Arma Anugerah Abadi Sei Rampah Branch, namely with the highest value of support and confidence are the Chocolate Cheese Wrap Bread and the Pres coconut Wrap Bread with a support value of $17 \%$ and a confidence value of $77 \%$.

Key Word-Apriori algorithm; association rules; data mining.

Paujiah Nur Harahap is with the Informatic Engineering Departement of STMIK Pelita Nusantara, Medan, Indonesia (email paujiahnur11@gmail.com )

Sulindawaty, is with the Informatic Engineering Departement of STMIK Pelita Nusantara, Medan, Indonesia (email sulindawaty@gmail.com )

\section{PENDAhuluaN}

$\mathrm{T}$ EKNOLOGI informasi telah berkembang sangat pesat dan memberikan efek yang cukup besar di dalam kehidupan manusia. Pengaruh tersebut tidak lepas dari teknologi informasi seperti pada aspek perekonomian, kesehatan, pendidikan, bisnis, dan lainlain. Dalam aspek bisnis khususnya dibidang penjualan, suatu pebisnis akan mengumpulkan berbagai informasi untuk memperoleh keuntungan yang maksimal dan meminimalkan kerugian.

PT.Arma Anugerah Abadi merupakan salah satu industri yang beroperasi dalam bidang produksi dan penjualan makanan yang menyediakan berbagai macam produk roti dan kue. Terdapat lebih dari 50 toko yang tersebar di beberapa daerah, seperti Sumatera Utara, Pekan Baru dan Aceh.Berbagai macam produk yang diproduksi dan ditawarkan kepada pelanggan mulai dari produk roti dengan ukuran besar hingga kue yang berukuran kecil. Setiap hari PT.Arma Anugerah Abadi melakukan kegiatan seperti penerimaan pesanan, transaksi penjualan, penyediaan stok produk, dan lainlain.

Pada proses pengolahan data transaksi penjualan pada PT. Arma Anugerah Abadi belum dapat memberikan informasi tentang pola kebiasaan belanja pelanggan, pengolahan data tersebut belum dapat memberikan informasi tentang pola atau hubungan sekumpulan item yang dibeli oleh pelanggan. Sehingga pihak perusahaan kesulitan dalam mengetahui setiap produk yang laku terjual. Metode sederhana yang dilakukan dalam menganalisa kebiasaan belanja pelanggan sangan sulit dan belum dilakukan secara optimal, karena perkembangan data yang semakin lama semakin bertambah.

Penelitian terdahulu, pada analisis data penjualan produk elektronik dengan menggunakan algoritma apriori menyimpulkan data penjualan produk laptop di kreditplus dengan menentukan minimum support $30 \%$ dan minimal confidence $60 \%$ mendapatkan hasil penjualan barang elektronik paling banyak dipasarkan adalah Acer dan Toshiba [2]. 
Berdasarkan penelitian tersebut, peneliti mencoba untuk membuktikan penelitian sebelumnya dan meningkatkan keakurasian data agar agar infomasi baru yang dihasilkan dapat meningkatkan pengetahuan tentang keranjang belanja pelanggan dan kebiasaan pelanggan dalam membeli suatu produk, dan dapat mengetahui produk yang paling sering laku terjual. Tujuan penelitian dalam memprediksi transaksi penjualan pada PT.Arma Anugerah Abadi adalah: Untuk mengetahui hasil pengolahan data keranjang belanja pada penjualan produk roti dan kue. Untuk menerapkan algoritma Apriori untuk mengetahui penjualan produk roti (bakery) pada PT.Arma Anugerah Abadi Cabang Sei Rampah yang paling banyak terjual. Untuk merancang aplikasi penerapan data mining dalam memprediksi transaksi penjualan menggunakan algoritma apriori.

Manfaat Penelitian dalam memprediksi transaksi penjualan pada PT. Arma Anugerah Abadi adalah: Memudahkan perusahaan mendapatkan informasi terhadap produk yang sering dibeli oleh konsumen. Sebagai bahan evaluasi bagi pihak peusahaan dalam perbaikan sistem yang sekarang diterapkan. Sebagai alat bantu pihak perusahaan mempunyai sistem pendukung keputusan dalam menentukan barang yang paling sering terjual.

\section{LANDASAN TEORI}

\subsection{Data Mining}

Data mining sebagai proses menemukan informasi yang berguna dari gudang basis data yang besar. Data mining juga dapat diartikan sebagai pengekstrakan informasi dari sekumpulan data besar untuk membantu dalam pengambilan keputusan [1].

Data mining atau knowledge discovery in database (KDD) adalah proses resourcing dan penggunaan data untuk menemukan pola atau hubungan dari sekumpulan data berukuran besar. Hasil dari proses data mining dapat digunakansebagai evaluasi pengambilan keputusan dimasa depan [3].

Definisi publik dari data mining merupakan metode pencarian pola-pola pengetahuan yang tersembunyi yang tidak diketahui sebelumnya dari suatu sekumpulan data yang sangat besar dalam database, data werehouse, atau media penyimpanan lainnya [4].

Data mining digunakan untuk menggali nilai tambah berupa informasi yang tidak diketahui secara manual dari suatu basis data. Informasi diperoleh dengan cara mengektrasi dan mengenali pola yang penting atau menarik dari data yang terdapat dalam basis data [5].

\subsection{Algoritma Apriori}

Algoritma apriori merupakan salah satu jenis aturan asosiasi pada data mining yang menerangkan asosiasi terhadap beberapa atribut sering disebut affinity analysis atau market basket analysis. Analisis asosiasi atau association rule mining adalah cara data mining untuk menemukan aturan suatu kombinasi item [6]. Pada tahap analisis asosiasi, para peneliti tertarik untuk mendapatkan algoritma yang efisien adalah analisis pola frequensi tinggi (frequent pattern mining). Tingkat kepentingan sebuah asosiasi dapat diketahui dengan dua tolak ukur, yaitu : support dan confidence. Support (nilai penunjang) merupakan persentase kombinasi item tersebut dalam database, sementara confidence (nilai kepastian)merupakan kuatnya relasi antar-item dalam aturan asosiasi.

Metodologi dasar analisis asosiasi dibagi kedalam dua tahap [7]:

1. Analisa pola frekuensi tinggi

Tahapan ini mencari kombinasi item yang memenuhi syarat minimum dari nilai support dalam database. Nilai support sebuah item diperoleh dengan rumus:

$$
\text { Support }(A)=\frac{\text { Jumlah transaksi mengandung A }}{\text { Total transaksi }}
$$

Sedangkan pada dua itemset atau lebih diperoleh dengan rumus:

$$
\text { Support }(A, B)=\frac{\text { Jumlah transaksi mengandung A dan B }}{\text { Total transaksi }}
$$

\section{Penciptaan aturan assosiatif}

Setelah semua pola frekuensi tinggi ditemukan, barulah dicari aturan assosiatif yang memenuhi syarat minimum untuk confidence dengan menghitung confidence aturan assosiatif A-B. Nilai confidence dari aturan $\mathrm{A}-\mathrm{B}$ diperoleh dari rumus:

$$
\text { Confidence } \mathrm{P}(\mathrm{B} \mid \mathrm{A})=\frac{\text { Jumlah transaksi mengandung A dan } \mathrm{B}}{\text { Jumlah transaksi mengandung A }}
$$

Dari proses pembentukan aturan asosiasi maka akan diperoleh nilai confidence dari setiap item set, dan kemudian ditentukan nilai minimum confidence untuk memperoleh rules association.

\subsection{Aturan assosiasi (Association rules)}

Aturan asosiasi (Association rules) merupakan suatu metode yang digunakan dalam mencari pola yang sering muncul pada sekumpulan transaksi, dimana setiap transaksi terdiri dari beberapa item atau produk[8]. Analisa asosiasi mining adalah teknik data mining untuk menemukan aturan asosiatif antara suatu kombinasi dari beberapa item [9].

\section{Metode Penelitian}

Kerangka penelitian merupakan konsep-konsep yang akan diukur atau diteliti pada penelitian yang akan dilakukan. Pada penelitian ini, peneliti akan menjelaskan cara melakukan penelitian dengan urutan alur penelitian yang dibuat secara sistematis. Kerangka kerja penelitian ini ialah step-step dalam pencarian dan pembahasan yang dilakukan untuk penyelesaian masalah yang akan dibahas.

Adapun kerangka kerja penelitian dapat dilihat pada gambar 1 . 


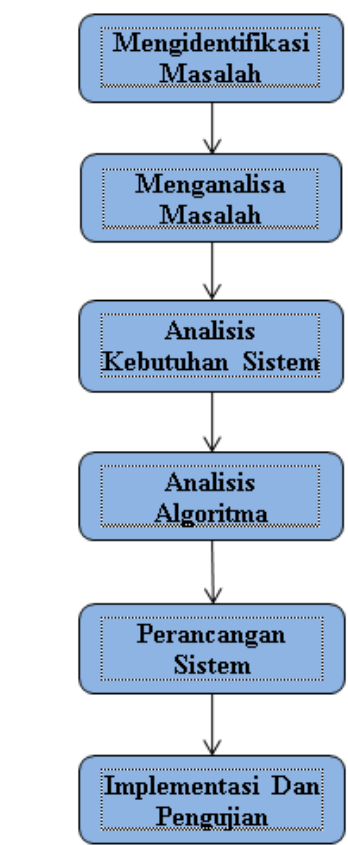

Gambar 1. Kerangka Kerja Penelitian

\section{AnAlisa dan PERANCANGan}

Pada penelitian ini, data yang dianalisa adalah data transaksi pada bulan Januari 2019 terhadap 100 data transaksi terdiri dari 30 item.

Tabel 1. Daftar Produk Roti

\begin{tabular}{|c|c|c|}
\hline No & $\begin{array}{c}\text { Kode } \\
\text { Produk }\end{array}$ & Nama Produk \\
\hline 1 & A01 & Bika Ambon Besar \\
\hline 2 & A02 & Lapis Legit Gulung Besar \\
\hline 3 & A03 & Lapis Legit Gulung Mini \\
\hline 4 & A04 & Blondi Spesial Besar \\
\hline 5 & A05 & Blondi Spesial Mini \\
\hline 6 & A06 & Blonde Spesial Sedang \\
\hline 7 & A07 & Donut Isi Coklat \\
\hline 8 & A08 & Donut Biasa \\
\hline 9 & A09 & Donut Sate \\
\hline 10 & A10 & Caramel Besar \\
\hline 11 & A11 & Chiffon Cake Ceres Kacang \\
\hline 12 & $\mathrm{~A} 12$ & Roti Bungkus Coklat Keju \\
\hline 13 & A13 & Roti Bungkus Pres Kelapa \\
\hline 14 & A14 & Roti Fla Keju \\
\hline 15 & A15 & Roti Bungkus Kacang Hijau \\
\hline 16 & A16 & Roti Sosis Abon Sapi \\
\hline 17 & A17 & Roti Sosis Panjang \\
\hline 18 & A18 & Roti Coklat Kismis \\
\hline 19 & A19 & Roti Kacang Merah \\
\hline 20 & A20 & Roti Kacang Hijau \\
\hline 21 & $\mathrm{~A} 21$ & Roti Manis Kosong \\
\hline 22 & A22 & Brownis Panggang Mini \\
\hline 23 & A23 & Brownis Panggang Panjang \\
\hline
\end{tabular}

\begin{tabular}{lcl}
\hline \hline No & $\begin{array}{c}\text { Kode } \\
\text { Produk }\end{array}$ & \multicolumn{1}{c}{ Nama Produk } \\
\hline 24 & A24 & Brownis Kukus Abon \\
25 & A25 & Brownis Cup \\
26 & A26 & Bolu Gulung Capucino Besar \\
27 & A27 & Kue Basah \\
28 & A28 & Choco Crumb \\
29 & A29 & BFR Sedang \\
30 & A30 & Bagelan Ori \\
\hline \hline
\end{tabular}

Langkah 1: Misalkan diberikan nilai minimum support $\geq$ 10\% dari 100 transaksi penjualan maka akan diperoleh data yang memenuhi nilai minimum support. Nilai support diperoleh dengan rumus sebagai berikut:

$$
\begin{gathered}
\text { Support }(\mathrm{A})=\frac{\text { Jumlah transaksi mengandung A }}{\text { Total transaksi }} \\
\text { Support(A01) }=\frac{29}{100} \times 100 \%=29 \% \\
\text { Support(A02) }=\frac{11}{100} \times 100 \%=11 \% \\
\text { Support(A03) }=\frac{21}{100} \times 100 \%=21 \% \\
\text { Support(A04) }=\frac{31}{100} \times 100 \%=31 \% \\
\text { Support(A05) }=\frac{12}{100} \times 100 \%=12 \%
\end{gathered}
$$

Tabel 2. Memenuhi Support 1-ItemSet

\begin{tabular}{cccc}
\hline \hline No & $\begin{array}{c}\text { Kode } \\
\text { Produk }\end{array}$ & Jumlah & $\begin{array}{c}\text { Nilai } \\
\text { Support }\end{array}$ \\
\hline 1 & A01 & 29 & $29 \%$ \\
2 & A02 & 11 & $11 \%$ \\
3 & A03 & 21 & $21 \%$ \\
4 & A04 & 31 & $31 \%$ \\
5 & A05 & 12 & $12 \%$ \\
6 & A07 & 27 & $27 \%$ \\
7 & A08 & 32 & $32 \%$ \\
8 & A09 & 26 & $26 \%$ \\
9 & A10 & 16 & $16 \%$ \\
10 & A12 & 22 & $22 \%$ \\
11 & A13 & 34 & $34 \%$ \\
12 & A16 & 11 & $11 \%$ \\
\hline \hline
\end{tabular}

Langkah 2: Proses selanjutnya yaitu mencari nilai support 2 itemset dengan minimum support $\geq 10 \%$ dari 100 data transaksi. Dapat diselesaikan dengan rumus:

Support $(\mathrm{A}, \mathrm{B})=$

Jumlah transaksi mengandung A dan B

Total transaksi

Support $(\mathrm{A} 01 \mid \mathrm{A} 03)=\frac{17}{100} \times 100 \%=17 \%$ 
Tabel 3. Memenuhi Support 2-ItemSet

\begin{tabular}{clccc}
\hline \hline No & \multicolumn{2}{l}{ Kombinasi 2 Item } & Jumlah & $\begin{array}{c}\text { Nilai } \\
\text { Support }\end{array}$ \\
\hline 1 & A01 & A03 & 17 & $17 \%$ \\
2 & A01 & A04 & 15 & $15 \%$ \\
3 & A01 & A13 & 13 & $13 \%$ \\
4 & A03 & A04 & 10 & $10 \%$ \\
5 & A04 & A11 & 12 & $12 \%$ \\
6 & A04 & A13 & 10 & $10 \%$ \\
7 & A07 & A08 & 19 & $19 \%$ \\
8 & A07 & A09 & 15 & $15 \%$ \\
9 & A08 & A09 & 18 & $18 \%$ \\
10 & A09 & A13 & 12 & $12 \%$ \\
11 & A12 & A13 & 17 & $17 \%$ \\
\hline \hline
\end{tabular}

Langkah 3: Pembentukan aturan asosiatif

Setelah dilakukan analisa dan ditemukan semua pola frekuensi tinggi, kemudiam mencari aturan asosiasi yang memnuhi minimum confidence $\geq 35 \%$. Dapat diselesaikan dengan rumus:

\begin{tabular}{|c|c|c|c|c|}
\hline \multicolumn{5}{|c|}{$\begin{array}{c}\text { Confidence } \mathrm{P}(\mathrm{B} \mid \mathrm{A})= \\
\text { Jumlah transaksi mengandung A dan B }\end{array}$} \\
\hline \multicolumn{5}{|c|}{ Jumlah transaksi mengandung A } \\
\hline \multirow{2}{*}{\multicolumn{5}{|c|}{$\begin{array}{l}\text { Confidence } P(\mathrm{~A} 01 \mid \mathrm{A} 03)=\frac{17}{29} \times 100 \%=59 \% \\
\text { Confidence } \mathrm{P}(\mathrm{A} 01 \mid \mathrm{A} 04)=\frac{15}{29} \times 100 \%=52 \%\end{array}$}} \\
\hline & & & & \\
\hline \multicolumn{5}{|c|}{ Tabel 4. Aturan Asosiasi (Asociation Rule) } \\
\hline No & & $\begin{array}{l}\text { nasi } 2 \\
n\end{array}$ & Support & $\begin{array}{c}\text { Nilai } \\
\text { Confidence }\end{array}$ \\
\hline 1 & A01 & $\mathrm{A} 03$ & $17 \%$ & $59 \%$ \\
\hline 2 & $\mathrm{~A} 01$ & A04 & $15 \%$ & $52 \%$ \\
\hline 3 & $\mathrm{~A} 01$ & A09 & $13 \%$ & $45 \%$ \\
\hline 4 & $\mathrm{~A} 03$ & A04 & $10 \%$ & $48 \%$ \\
\hline 5 & A04 & A11 & $12 \%$ & $39 \%$ \\
\hline 6 & A07 & A08 & $19 \%$ & $70 \%$ \\
\hline 7 & A07 & A09 & $14 \%$ & $52 \%$ \\
\hline 8 & A08 & A09 & $18 \%$ & $56 \%$ \\
\hline 9 & A09 & A13 & $12 \%$ & $46 \%$ \\
\hline 10 & $\mathrm{~A} 12$ & A13 & $17 \%$ & $77 \%$ \\
\hline
\end{tabular}

Dari tabel 4 diatas diperoleh 10 aturan asosiasi yang memenuhi nilaiminimum support dan nilai minimum confidence. Sehingga dapat disimpulkan bahwa nilai tertinggi dari aturan asosiasi adalah kombinasi dari Roti Bungkus Coklat Keju dan Roti Bungkus Pres Kelapa dengan nilai support $17 \%$ dan niali confidence $77 \%$.

Merancang sistem untuk mengetahui hasil dari pengolahan data transaksi penjualan menggunakan algoritma apriori dengan menggunakan use case diagram, activity diagram, class diagram, dan sequence diagram.

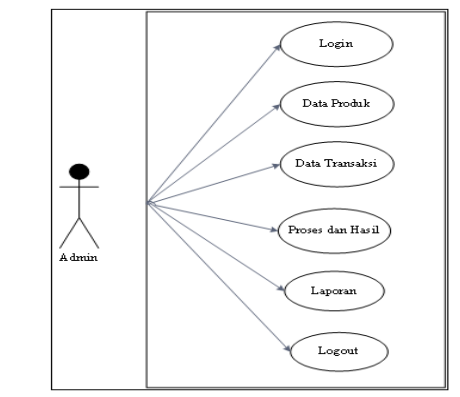

Gambar 2. Use Case Diagram Sistem Apriori

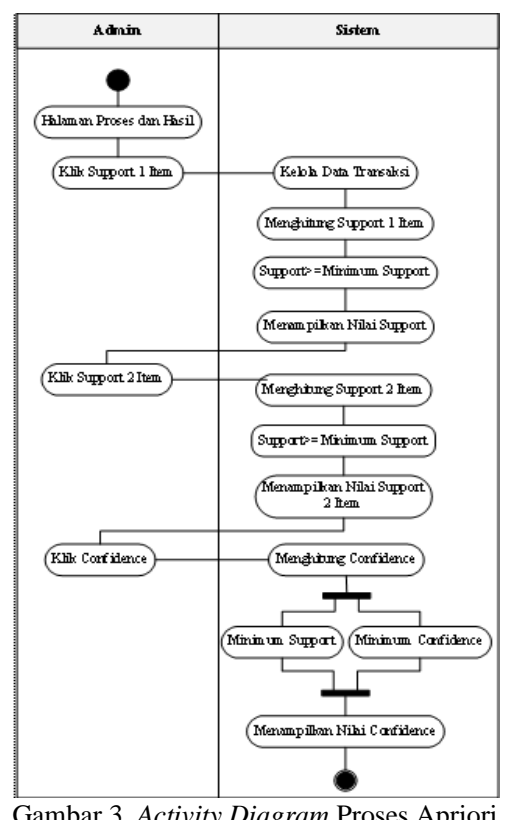

Gambar 3. Activity Diagram Proses Apriori

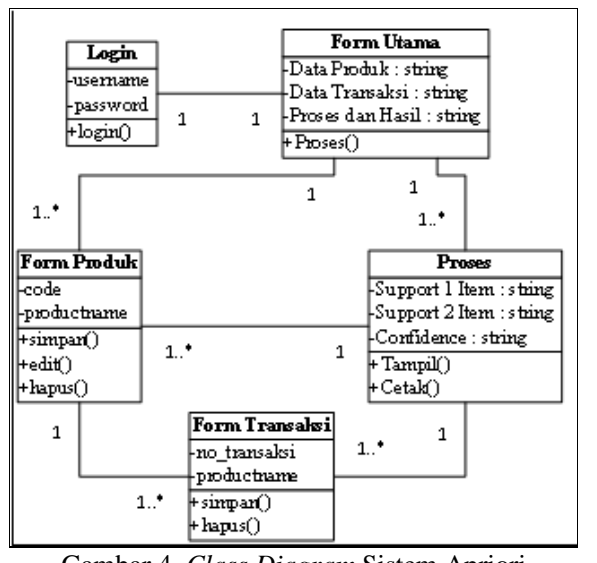

Gambar 4. Class Diagram Sistem Apriori

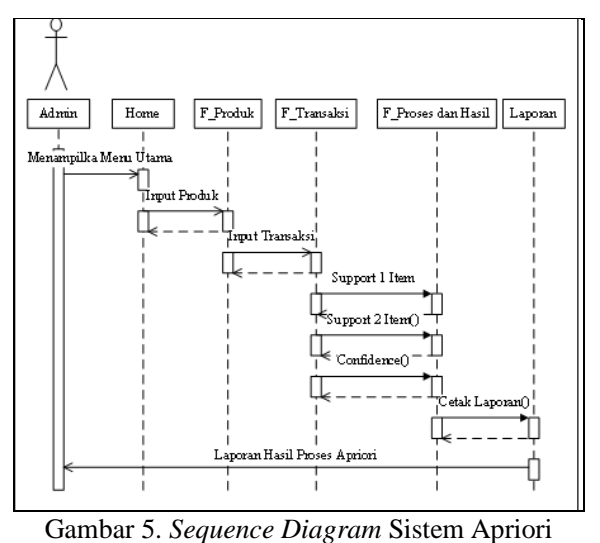

MATICS Volume. 11, No. 2, September 2019 


\section{IMPLEMENTASI SISTEM}

Implementasi Sistem Tahap implementasi sistem merupakan tahap berdasarkan pada hasil analisa dan perancangan sebelumnya yang dimasukkan ke dalam suatu bentuk bahasa pemrograman pada komputer untuk diolah, kemudian komputer menjalankan fungsi-fungsi yang telah didefenisikan.Pada menu utama berisi data produk dengan menginputkan data produk dan meniyimpannya kedalam database, Gambar 6. Dalam menu utama berisi data transaksi dengan menginputkan data transaksi dan menyimpannya kedalam database, Gambar 7. Dalam menu utama berisi hasil dan proses apriori berupa nilai support dan confidence, Gambar 8 .

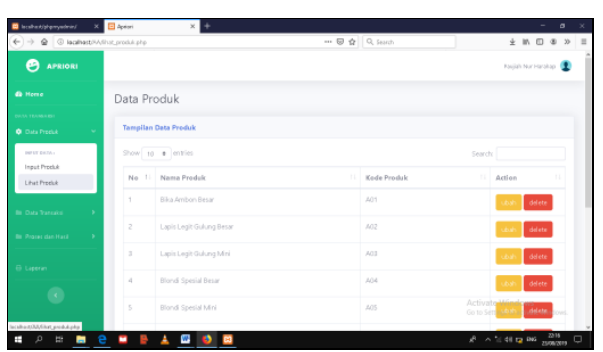

Gambar 6. Form Data Produk

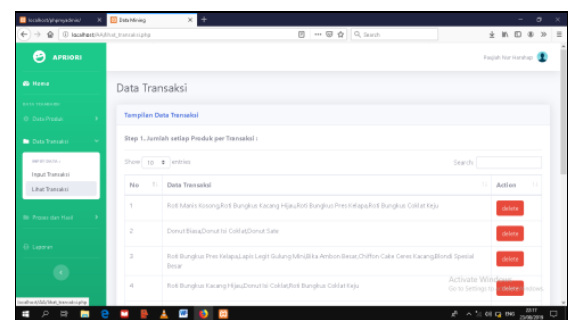

Gambar 7. Form Data Transaksi

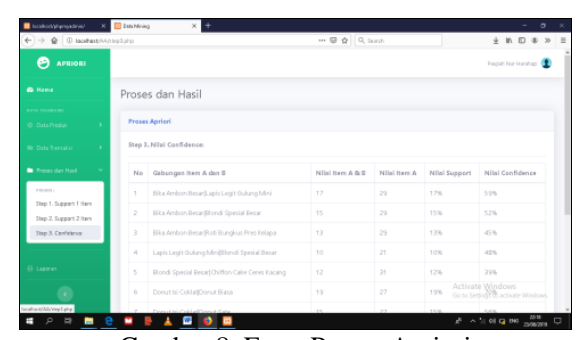

Gambar 8. Form Proses Apriori

Pada analisis apriori memiliki tombol cetak pada form laporan yang dapat digunakan agar hasil dari analisa apriori dapat ditampilkan dalam bentuk aturan asosiasi. Berikut ini hasil laporan analisa apriori dapat dilihat pada gambar 9 .

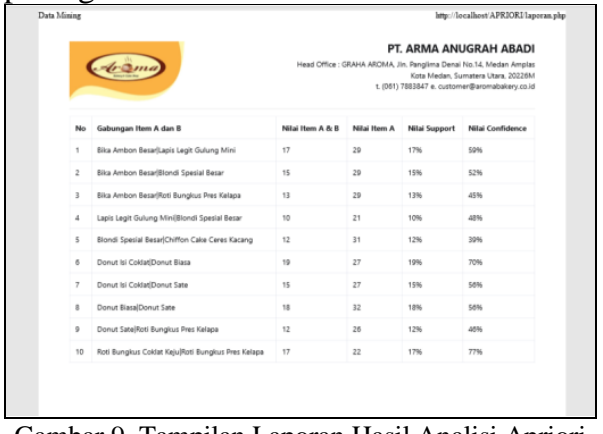

Gambar 9. Tampilan Laporan Hasil Analisi Apriori

\section{KESIMPULAN}

Berdasarkan penelitian dan implementasi yang dilakukan pada sistem implementasi data mining dalam memprediksi transaksi penjualan dengan menggunakan algoritma apriori maka dapat diambil kesimpulan sebagai berikut: Analisa asosiasi dengan algoritma apriori dapat menemukan aturan asosiasi untuk kombinasi penjualan produk roti, serta mengetahui produk roti yang paling banyak diminati oleh pelanggan. Penerapan data mining menggunakan algoritma apriori sangat efisien dan dapat mempercepat proses pembentukan kecendrungan pola kombinasi itemset dari hasil transaksi penjualan produk roti pada PT. Arma Anugerah Abadi Cabang Sei Rampah, yaitu dengan nilai support dan confidence tertinggi adalah Roti Bungkus Coklat Keju dan Roti Bungkus Pres Kelapa. Pengujian sistem yang telah dirancang untuk memprediksi transaksi penjualan pada PT. Arma Anugerah Abadi Cabang Sei Rampah dengan menggunakan bahasa pemrograman PHP dan database MySql menghasilkan kombinasi item dan nilai persentase dari tiap data transaksi.

\section{REFERENSI}

[1] Prasetyo, E. 2017. "Data Mining: Konsep dan Aplikasi Menggunakan MATLAB”, Yogyakarta: C.V Andi Offset.

[2] Pane, D.K. 2013. "Implementasi Data Mining Pada Penjualan Produk Elektronik Denagan Menggunakan Algoritma Apriori”. Pelita Informatika Budi Darma, Vol.4 (3), 25-29.

[3] Putria, N.E. 2018. "Data Mining Penjualan Tiket Pesawat Menggunakan Algoritma Apriori Pada Terminal Tiket Batam Tour \& Travel”. Computer Based Information System Journal, Vol.06 (01), 29-38.

[4] Rahmawati, F., Merlina, N. 2018. "Metode Data Mining Terhadap Dta Penjualan Sparepart Mesin Fotocopy Menggunakan Algoritma Apriori". Jurnal Penelitian Ilmu Komputer, System Embedded \& Logic, Vol.6 (1), 9-20.

[5] Sulindawaty, Muhammad Zarlis, Niskarto Zendrato. 2018. "Strategi Peningkatan Penjualan Buku Pada PT. Tiga Serangkai Internasional Dengan Metode Clustering”. Seminar Nasional Teknologi Informasi dan Komunikasi STI\&K, Vol 2. 102-110.

[6] Vulandari, R.T. 2017. "Data Mining: Teori dan Aplikasi Rapidminer”. Surakarta: PENERBIT GAVA MEDIA, 2017.

[7] Wijayanti, A. 2017. "Analisis Hasil Implementasi Data Mining Menggunakan Algoritma Apriori Pada Apotek”. Jurnal Edukasi dan Penelitian Informatika (JEPIN), Vol.3 (1), 60-64.

[8] Anas, A. 2015. "Algoritma Apriori untuk Mendapatkan Perilaku Konsumen Dalam Pembelian Barang”. Jurnal Sains dan Informatika, Vol.1 (02), 45-59.

[9] M. Ikhsan, M. Dahria, Sulindawaty. 2011. "Penerapan Association Rule dengan Algoritma Apriori Pada Proses Pengelompokan Barang di Perusahaan Reatil". 